\title{
Study on Effects of CSI 300 Stock Index Futures on Chinese Stock Market Volatility
}

\author{
Yiwen $\mathrm{Hu}^{1, \mathrm{a}}$ \\ ${ }^{1}$ Economics College, Shanghai University, Shanghai, China, 200444 \\ ahelenhuyiwen@163.com
}

\begin{abstract}
Keywords: CSI 300 Stock Index Futures, Volatility, GARCH model, TARCH model
Abstract. At present, there is a growing concern on the effects of CSI 300 stock index futures on Chinese stock market volatility. This paper mainly studies the effects of introduction and price volatility of stock index futures on Chinese stock market volatility, which is based on the analysis of CSI 300 index. Based on the TARCH model, we find that the introduction of CSI 300 stock index futures reduce the asymmetric volatility of the stock market. Based on the GARCH model, we find that the price volatility of CSI 300 stock index futures have no significant effect on the volatility of the stock market.
\end{abstract}

\section{Introduction}

After a long period of preparations, the CSI 300 stock index futures has officially launched on April 16, 2010.

There is a growing concern on the effects of CSI 300 stock index futures on Chinese Stock Market Volatility. However, the present study has not yet come to a unified conclusion. The first opinion is that the introduction has no significant effect on the volatility of the stock market. Pericli and Koutmos (1997) use EGARCH and EGARCH-M model and find that the introduction of stock index futures has no significant effect on the conditional volatility and unconditional volatility of the stock market, based on the analysis of the S\&P 500 index. Baldauf and Santoni (1991) use the data from 1975 to 1989 of the Chicago Futures Market and New York Stock Exchange and conclusion is that the introduction of the S\&P 500 index has no significant effect on the volatility of the stock market, despite that it speeds up the reaction of supply-demand relationship of the stock market. The second opinion is that the introduction increases the volatility of the stock market. Antoniou and Holmes (1995) have a research on the FR-SE100 index and find that stock index futures increase the volatility of the stock market, but it also improves the response speed and quality of the spot market information. Robbai and Bhuyan (2005) conclude that the introduction of stock index futures has attracted many ignorant irrational investors, which increases the volatility of the stock market. The third opinion is that the introduction decreases the volatility of the stock market. Bessembinder and Seguin (1996) find that the introduction of futures market decreases the volatility of the spot market, based on the analysis on the S\&P 500 index. S.L. Zhou and L. Gui (2011) study on the asymmetric effect of stock index futures on the volatility of the stock market, and find that the introduction of stock index futures decreases the asymmetric volatility of the Chinese stock market.

Based on the analysis of CSI 300 index, this paper uses TARCH model and GARCH model to study the effects of introduction and price volatility of stock index futures on stock market volatility.

\section{Data description and stability test}

Since the constituent stocks of CSI 300 index contain both Shanghai Stock Exchange and Shenzhen Stock Exchange and have 10 different industries, we can say that CSI 300 index is a barometer of the overall trend of Chinese stock market. Therefore, this paper uses CSI 300 index to represent the overall trend of the stock market and its closing price is denoted as $P_{t}$. In order to analyze the impact of stock index futures on the stock market volatility, this paper selects two sets of data to analyze. The first group is used to analyze the effect of the introduction of stock index futures: select day data of 1702 days before and after the introduction of stock index futures, which is from January 2, 2008 to 
December 31, 2014. ${ }^{1}$ Moreover, we include a dummy variable $D_{t}$ to distinguish between before and after the introduction of stock index futures. The second group is used to analyze the effect of the price volatility of stock index futures: select day data of 1143 days which is from March 19, 2010 to December 31, 2014 and also includes a dummy variable $D_{t} \cdot{ }^{2}$ Let $\mathrm{r}$ be the logarithmic return rate of the CSI 300 index, and the calculation formula is as follows:

$$
r=\ln P_{t}-\ln P_{t-1}
$$

Then, we do the ADF unit root test for the logarithmic return series and the results show that $\mathrm{t}$ values are -40.46 and -33.82 , $\mathrm{P}$ values are both 0.0000 , less than $1 \%$ significant level. Thus, the the logarithmic return series do not have unit root effect. Namely, the time series are stationary.

\section{The establishment of GARCH models}

The logarithmic return series have a typical financial time series characteristics of leptokurtic and fat tailed, so we can consider building GARCH model for it. First, we do the autocorrelation analysis of the logarithmic return series and find that the $\mathrm{P}$ values of all lag orders are greater than $5 \%$. Thus, there is no significant autocorrelation at level $5 \%$.

Therefore, we can establish random walk model and the mean equation is as follows:

$$
\ln P_{t}=\alpha_{0} \ln P_{t-1}+s_{t}
$$

\section{The effect of the introduction of CSI 300 stock index futures}

Due to the asymmetric volatility of stock return series, that is the volatility of stock return series when the stock price decline is greater than the volatility when the stock price increase. Thus, we use TARCH model to describe this phenomenon. The equation is as follows:

$$
\sigma_{z}^{2}=\omega+\sum_{i=1}^{p} \alpha_{i} \varepsilon_{t-i}^{2}+\sum_{j=1}^{q} \beta_{j} \sigma_{z-j}^{2}+\sum_{k=1}^{r} \gamma_{k} s_{t-k}^{2} I_{t-k}
$$

In the above equation, $\sigma_{t}^{2}$ is conditional variance, $\omega$ is constant term and $\varepsilon_{t}$ is random error term. In order to guarantee $\sigma_{z}^{2}>0, \alpha_{i}, \beta_{j}, \gamma_{k}$ must be non-negative. $\sum_{k=1}^{r} \gamma^{k} \varepsilon_{t-k}^{2} I_{t-k}$ reflects leverage effect, which represents the effect of good news and bad news of preceding $\mathrm{k}$ periods to the conditional variance. The good news has only $\sum_{i=1}^{p} \alpha_{i}$ times impact, but the bad news has (

$\left.\sum_{i=1}^{p} \alpha_{i}+\sum_{k=1}^{r} \gamma_{k}\right)$ times impact. $I_{t-k}$ is dummy variable, $I_{t-k}=1$ when $\varepsilon_{t-k}<0$, and $I_{t-k}=0$ when $\varepsilon_{t-k}>0$. If $\gamma_{k}$ is significantly not equal to 0 , then it represents that there is leverage effect. Moreover, we include a dummy variable $D_{z}$ to distinguish between before and after the introduction of stock index futures. Variance equation plus dummy variables $D_{t}$ can be expressed as follows:

$$
\sigma_{t}^{2}=\omega+\sum_{i=1}^{p} \alpha_{i} \varepsilon_{t-i}^{2}+\sum_{j=1}^{q} \beta_{j} \sigma_{t-j}^{2}+\sum_{k=1}^{r} \gamma_{k} s_{t-k}^{2} I_{t-k}+\theta D_{t}
$$

$D_{t}=\left\{\begin{array}{c}1, \text { before the introduction } \\ 0, \text { after the introduction }\end{array}\right.$ 


\section{The effect of the price volatility of CSI 300 stock index futures}

This part we use GARCH model and the reasons are explained in empirical analysis. A specific $\operatorname{GARCH}(p, q)$ model is expressed as follows:

$$
\begin{aligned}
& l n P_{t}=\alpha_{0} l n P_{t-1}+\varepsilon_{t} \\
& \sigma_{t}^{2}=\beta_{0}+\sum_{i=1}^{q} \beta_{i} \varepsilon_{t-i}^{2}+\sum_{j=1}^{p} \gamma_{j} \sigma_{t-j}^{2}
\end{aligned}
$$

In the above equations, $\varepsilon_{i}$ is random error term. $\beta_{i}$ as the coefficient of lag residuals is an information coefficient, representing the importance of the recent market news, used to measure the impact of the previous period volatility information to spot volatility. $\gamma_{j}$ is the coefficients of the conditional hetero variance of the lag period, used to measure the cumulative impact of previous period volatility. Then, we include a dummy variable $D_{t}$ to represent the price volatility of CSI 300 stock index futures. $\operatorname{GARCH}(\mathrm{p}, \mathrm{q})$ model plus dummy variables $D_{\tau}$ can be expressed as follows:

$$
\begin{aligned}
& \ln P_{t}=\alpha_{0} l n P_{t-1}+s_{t} \\
& \sigma_{t}^{2}=\beta_{0}+\sum_{i=1}^{q} \beta_{i} \varepsilon_{t-i}^{2}+\sum_{j=1}^{p} \gamma_{j} \sigma_{t-j}^{2}+\theta D_{t} \\
& D_{t}=\left\{\begin{array}{l}
1, \text { when the price of stock index futures increases } \\
0, \text { when the price of stock index futures decreases }
\end{array}\right.
\end{aligned}
$$

\section{Empirical analysis based on the CSI 300 Index}

\section{The effect of the introduction of CSI 300 stock index futures}

First, we use least square method to model the mean equation of GARCH model and the result is as follows:

$$
\ln P_{t}=1.00 \ln P_{t-1}+\varepsilon_{t}
$$

The $t$ value of independent variable coefficient is $17910.41, \mathrm{p}$ value is 0.0000 , the fitting coefficient $R^{2}=0.9918, \log$ likelihood value is $4403.10, \mathrm{AIC}=-5.17, \mathrm{SC}=-5.17$. Thus, the coefficient of this equation is significantly positive, and $\boldsymbol{R}^{2}$ is quite high. The residual plot is as follows: 


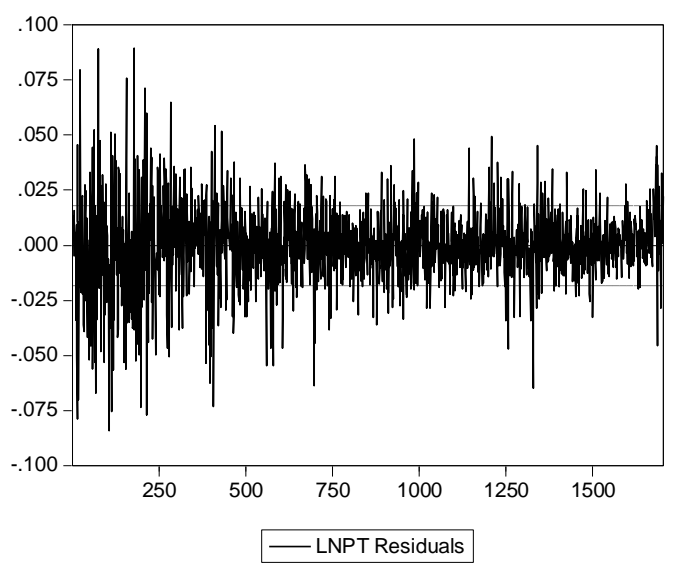

Fig.1 The residual plot of equation

It can be seen from the figure that the residuals of eqaution show obvious fluctuation aggregation, which indicates that the residual series may have conditional heteroskedasticity. Then, we do ARCH $\mathrm{LM}$ test for the equation, and the result when the lag order is 1 is that $\mathrm{P}$ value is 0.0000 , which indicates that we should reject the original hypothesis at $5 \%$ level of significance, and the residual series may have conditional heteroskedasticity. Therefore, $\operatorname{TARCH}(1,1)$ model is as follows:

$$
\sigma_{t}^{2}=\omega+\alpha \varepsilon_{t-1}^{2}+\gamma \varepsilon_{t-1}^{2} I_{t-1}+\beta \sigma_{t-1}^{2}+\theta D_{t}
$$

The estimation results of $\mathrm{TARCH}(1,1)$ model are shown in the following table:

Table 1 The estimation results of TARCH $(1,1)$ model

\begin{tabular}{|c|c|c|c|c|}
\hline & variable & coefficient & $\mathrm{Z}$ value & P value \\
\hline Mean equation & $\ln \boldsymbol{P}_{t-1}$ & 1.00 & 21847.53 & 0.0000 \\
\hline \multirow{5}{*}{ Variance equation } & $\omega$ & $5.44 \mathrm{E}-06$ & 4.35 & 0.0000 \\
\cline { 2 - 5 } & $\varepsilon_{t-\mathbf{1}}^{2}$ & 0.0375 & 4.78 & 0.0000 \\
\cline { 2 - 5 } & $\varepsilon_{t-1}^{2} L_{t-1}$ & 0.0364 & 3.70 & 0.0002 \\
\cline { 2 - 5 } & $\sigma_{t-1}^{2}$ & 0.9185 & 89.53 & 0.0000 \\
\cline { 2 - 5 } & $D_{t}$ & $8.02 \mathrm{E}-06$ & 3.42 & 0.0006 \\
\hline
\end{tabular}

It can be seen in the above table that the fitting coefficient $R^{2}=0.9918$, all the coefficients are significant, log likelihood value is $4609.55, \mathrm{AIC}=-5.41, \mathrm{SC}=-5.39$. Thus, the log likelihood value increases and the value of AIC and SC decrease, which indicates that $\operatorname{TARCH}(1,1)$ model fits the data better. Moreover, the leverage effect coefficient $\gamma$ is significantly positive at $1 \%$ level of significant, which indicates that the leverage effect is obvious, and the bad news results in greater volatility compared to good news. The coefficient $\beta$ presents the impact of the last period on the current period. In the above table we can see that $\beta$ is 0.9207 , thus the volatility of the last period is the main factor that affects the current volatility. The coefficient of dummy variable is significantly positive at $1 \%$ level of significant, which indicates that the volatility decreases after the introduction of stock index futures.

At last, we do ARCH LM test for the TARCH $(1,1)$ model, and the result when the lag order is 1 is that $\mathrm{P}$ value is bigger than 5\%, which indicates that we cannot reject the original hypothesis at 5\% level of significance, and the residual series do not have ARCH effect. Therefore, $\operatorname{TARCH}(1,1)$ model is better to simulate the volatility of the stock market. 


\section{The effect of the price volatility of CSI 300 stock index futures}

First, we use least square method to model the mean equation of GARCH model and the result is as follows:

$$
\ln P_{t}=1.00 \ln P_{t-1}+\varepsilon_{t}
$$

The $t$ value of independent variable coefficient is 19379.17 , $\mathrm{p}$ value is 0.0000 , the fitting coefficient $R^{2}=0.9891, \log$ likelihood value is $3281.59, \mathrm{AIC}=-5.74, \mathrm{SC}=-5.74$. Thus, the coefficient of this equation is significantly positive, and $R^{2}$ is quite high. The residual plot is as follows:

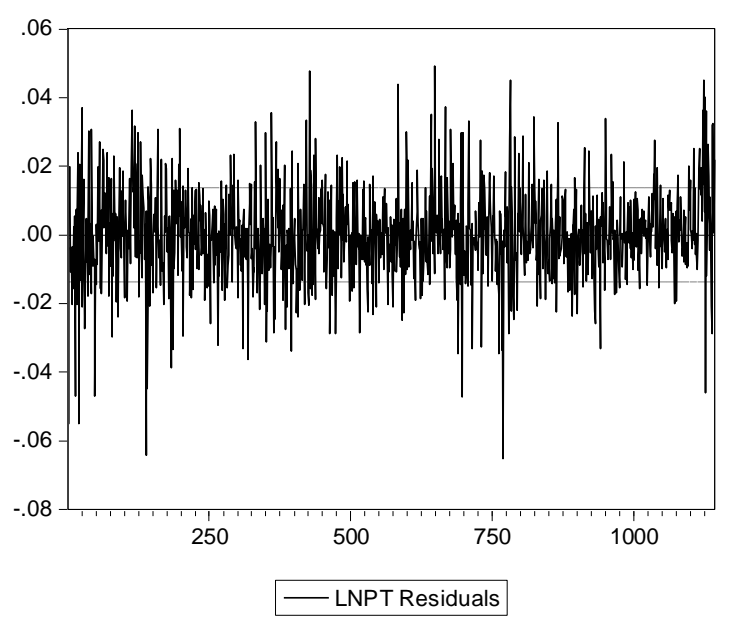

Fig.2 The residual plot of equation

It can be seen from the figure that the residuals of eqaution show obvious fluctuation aggregation, which indicates that the residual series may have conditional heteroskedasticity. Then, we do ARCH $\mathrm{LM}$ test for the equation, and the result when the lag order is 2 is that $\mathrm{P}$ value is 0.0003 , which indicates that we should reject the original hypothesis at $5 \%$ level of significance, and the residual series may have conditional heteroskedasticity. Therefore, $\operatorname{TARCH}(1,2)$ model is as follows:

$$
\sigma_{z}^{2}=\omega+\alpha_{1} \varepsilon_{\tau-1}^{2}+\alpha_{2} \varepsilon_{\tau-2}^{2}+\gamma \varepsilon_{z-1}^{2} I_{t-1}+\beta \sigma_{z-1}^{2}+\theta D_{z}
$$

The estimation results of $\operatorname{TARCH}(1,2)$ model are shown in the following table:

Table 2 The estimation results of TARCH $(1,2)$ model

\begin{tabular}{|c|c|c|c|c|}
\hline & variable & coefficient & Z value & P value \\
\hline Mean equation & $\ln P_{t-1}$ & 1.00 & 19954.80 & 0.0000 \\
\hline \multirow{5}{*}{ Variance equation } & $\omega$ & $5.37 \mathrm{E}-06$ & 1.654346 & 0.0981 \\
\cline { 2 - 5 } & $\varepsilon_{t-1}^{2}$ & -0.017947 & -1.058115 & 0.2900 \\
\cline { 2 - 5 } & $\varepsilon_{t-1}^{2} I_{z-1}$ & -0.007283 & -0.584736 & 0.5587 \\
\cline { 2 - 5 } & $\varepsilon_{t-2}^{2}$ & 0.064241 & 3.673237 & 0.0002 \\
\cline { 2 - 5 } & $\sigma_{t-1}^{2}$ & 0.928252 & 70.98412 & 0.0000 \\
\cline { 2 - 5 } & $D_{t}$ & $-2.27 \mathrm{E}-07$ & -0.040370 & 0.9678 \\
\hline
\end{tabular}

It can be seen in the above table that the fitting coefficient $\boldsymbol{R}^{2}=\mathbf{0 . 9 8 9 1}$, the leverage effect coefficient $\gamma$ is not significantly positive at $5 \%$ level of significant, which indicates that the leverage effect decreases after the introduction of stock index futures. Therefore, we change to use GARCH model to analyze the effect. Using $\operatorname{GARCH}(1,1), \operatorname{GARCH}(1,2), \operatorname{GARCH}(2,1), \operatorname{GARCH}(2,2)$ 
models to fit data and we finally choose $\operatorname{GARCH}(1,1)$ model based on the AIC and SC standards. The $\operatorname{GARCH}(1,1)$ model is as follows:

$$
\begin{aligned}
& \ln P_{t}=\alpha_{01} \ln P_{t-1}+s_{t} \\
& \sigma_{t}^{2}=\beta_{0}+\beta \varepsilon_{t-1}^{2}+\gamma \sigma_{t-1}^{2}+\theta D_{t}
\end{aligned}
$$

The estimation results of $\operatorname{GARCH}(1,1)$ model are shown in the following table:

Table 3 The estimation results of $\operatorname{GARCH}(1,1)$ model

\begin{tabular}{|c|c|c|c|c|}
\hline & variable & coefficient & $\mathrm{Z}$ value & P value \\
\hline Mean equation & $\ln \boldsymbol{P}_{t-1}$ & 1.00 & 20359.42 & 0.0000 \\
\hline \multirow{4}{*}{ Variance equation } & $\beta_{0}$ & $3.57 \mathrm{E}-06$ & 1.52 & 0.1297 \\
\cline { 2 - 5 } & $\varepsilon_{t-1}^{2}$ & 0.0350 & 4.58 & 0.0000 \\
\cline { 2 - 5 } & $\sigma_{t-1}^{2}$ & 0.9390 & 81.18 & 0.0000 \\
\cline { 2 - 5 } & $D_{t}$ & $2.29 \mathrm{E}-06$ & 0.5626 & 0.5737 \\
\hline
\end{tabular}

It can be seen in the above table that the fitting coefficient $R^{2}=0.9891$, all the coefficients are significant, $\log$ likelihood value is 3309.05, $\mathrm{AIC}=-5.78, \mathrm{SC}=-5.76$. Thus, the log likelihood value increases and the value of AIC and SC decrease, which indicates that $\operatorname{GARCH}(1,1)$ model fits the data better. The coefficient of dummy variable is not significantly positive at $5 \%$ level of significant, which indicates that the price volatility of stock index futures has no significant impact on the volatility of stock market.

At last, we do ARCH LM test for the $\operatorname{GARCH}(1,1)$ model, and the result when the lag order is 1 is that $\mathrm{P}$ value is bigger than 5\%, which indicates that we cannot reject the original hypothesis at $5 \%$ level of significance, and the residual series do not have ARCH effect. Therefore, $\operatorname{GARCH}(1,1)$ model is better to simulate the volatility of the stock market.

\section{Conclusions}

The introduction of CSI 300 index futures shows that Chinese financial derivatives market has begun to take shape, and it also plays an important role in promoting Chinese gradual opening up of financial markets. This paper mainly studies the effects of introduction and price volatility of stock index futures on Chinese stock market volatility, which is based on the analysis of CSI 300 index. Based on the TARCH model, we can find that the introduction of CSI 300 stock index futures reduce the asymmetric volatility of the stock market. Based on the GARCH model, we can find that the price volatility of CSI 300 stock index futures have no significant effect on the volatility of the stock market. This may be due to CSI 300 stock index futures exists for such a short time that the stock index futures market is not mature and the function of hedging is relatively small. Therefore, we can only say that the price volatility of stock index futures has no significant impact on Chinese stock market volatility in the short term.

\section{References}

[1] Pericli Andreas , Gregory Koutmos. Index Futures and Options and Stock Market Volatility[J].Journal of Futures Markets, 1997,17:957-974.

[2] Brad Baldauf, Santoni G.J., Stock Price Volatility: Some Evidence from an ARCH Model, The Journal of Futures Markets, 1991, 11 (2):191-200. 
[3] Antoniou A, Holmes P. Futures Trading, Information and Spot Price Volatility: Evidence for FT-SE100 Stock Index Futures Contract Using GARCH[J].Journal of Banking \& Finance, 1995.

[4] Mohammad G. Robbani, Rafiqul Bhuyan. Introduction of Futures and Options on a Stock Index and their Impact on the Trading Volume and Volatility: Empirical Evidence from the DJIA Components[J].Derivatives Use, Trading \& Regulation, 2005, 11(3): 246- 260.

[5] Bessembinder R, Seguim G W. Pricing Stock Index Futures with Stochastic Interest Bates[J]. Journal of Futures Markets , 1996.

[6] S.L. Zhou, L. Gui. An empirical study on the impact of stock index futures on the volatility of Chinese stock market[J].Journal of graduate students of Zhongnan University of Economics, 2011, 04: 58-63. 